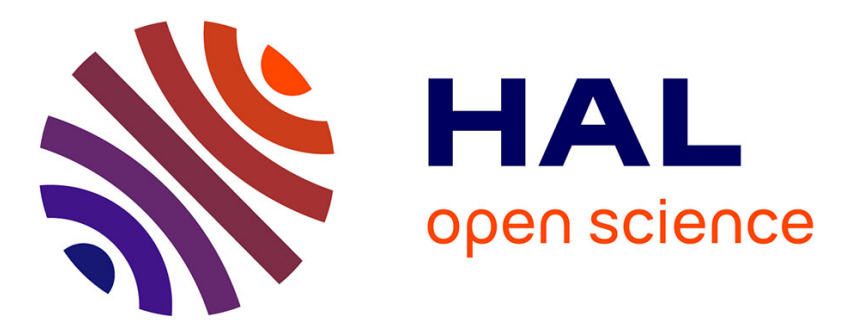

\title{
The prevalence of transitional object use in adolescence: is there a connection between the existence of a transitional object and depressive symptoms?
}

Ritva Erkolahti, Marjaana Nyström

\section{- To cite this version:}

Ritva Erkolahti, Marjaana Nyström. The prevalence of transitional object use in adolescence: is there a connection between the existence of a transitional object and depressive symptoms?. European Child and Adolescent Psychiatry, 2009, 18 (7), pp.400-406. 10.1007/s00787-009-0747-7 . hal-00478100

\author{
HAL Id: hal-00478100 \\ https://hal.science/hal-00478100
}

Submitted on 30 Apr 2010

HAL is a multi-disciplinary open access archive for the deposit and dissemination of scientific research documents, whether they are published or not. The documents may come from teaching and research institutions in France or abroad, or from public or private research centers.
L'archive ouverte pluridisciplinaire HAL, est destinée au dépôt et à la diffusion de documents scientifiques de niveau recherche, publiés ou non, émanant des établissements d'enseignement et de recherche français ou étrangers, des laboratoires publics ou privés. 
Ritva Erkolahti Marjaana Nyström

\section{The prevalence of transitional object use in adolescence: is there a connection between the existence of a transitional object and depressive symptoms?}

Received: 20 July 2007

Accepted: 24 November 2008

Published online: 16 February 2009
R. Erkolahti, MD, PhD, Docent $(\varangle)$

Medical Faculty

University of Oulu

Child Psychiatric Clinic

Satakunta Hospital District

Sairaalantie 3

28500 Pori, Finland

Tel.: +358-2/6276555

Fax: +358-2/6276509

E-Mail: ritva.erkolahti@satshp.fi

M. Nyström, MPsych

Department of Psychology

University of Turku

Turku, Finland
Abstract Objective The purpose of the study was to investigate the prevalence of the use of a transitional object (TO) in adolescence and its connection with depressive symptoms and mental distress in youth by gender. Method The study group consisted of 1,054 adolescents (465 boys, 589 girls) from normal comprehensive schools in Turku, a Finnish town with approximately 175,000 inhabitants. The mean age of both gender groups was 14.5 years (SD 0.5); respondents came from all social classes. Background and TO information was collected with questionnaires. Depressive symptoms and mental distress were explored by the children's depression inventory (CDI) and its subscales: low selfconfidence, anhedonia and sadness. Results Of all respondents, $29 \%(n=285)$ had a TO: $37 \%$ of girls and $18 \%$ of boys. The difference between genders was statistically significant. There was also a statistically significant gender dif- ference in the character of the TO reported: $72 \%$ of girls with a TO had a soft toy, whereas $49 \%$ of boys with a TO used hard objects, such as pens, hard toys or books. TO-users showed more depressive symptoms than non-users, but the difference was not statistically significant $(P=0.053)$. Significant differences were found in the CDI subscales: TO-users had more sadness than non-users and girls using a TO showed more sadness than non-using girls. TO-using boys did not differ from non-using boys with regard to sadness or the other CDI-subscales. Conclusions The use of a TO seems to be common in adolescence. Adolescents with more depressive symptoms more often used a TO. The sadness of girls using TOs requires attention.

Key words adolescence attachment - depression gender differences transitional object

\section{Introduction}

Infants and young children often form a strong F attachment to soft objects, such as teddy-bears, blankets, pillows and dolls. Winnicott [30-33] emphasizes the developmental significance of this attachment to what he calls a transitional object (TO).

Most studies of TOs and their developmental and psychological role have naturally dealt with infants and young children. There is, however, anecdotal evidence in support of the view that certain articles continue to play the role of a TO after childhood, and 
that the phenomenon is not uncommon among adolescents or even adults [3]. In the investigation by Bacharr et al. [4] of TO attachment in normal adolescents, $22 \%$ of respondents reported that they were currently attached to a TO. In some studies, an obvious long-lasting attachment to a certain object and TO use in adolescence have been connected to a greater number of psychiatric symptoms and diminished general wellbeing $[4,26]$. Markt and Johnson [21] found a connection between TO use and depression, especially when the adolescents felt lonely and feared falling asleep. Taking into account the introvert, uncommunicative and non-cooperative nature of many adolescents, an easily observed marker, such as an attachment to an object, can be helpful and sometimes crucial in identifying mental distress in normal adolescents [4].

\section{Developmental and psychological meaning of transitional objects}

According to Winnicott $[30,32,33]$, the TO helps the infant to learn to understand life outside himself or herself: it plays a role as the first "not me" possession and helps the child to re-establish his/her union with the mother after the separation process. One significant role of a TO is to comfort and soothe in a situation of separation anxiety, when the child is physically and psychologically separated from the mother. By means of the TO the child relates to the mother symbolically $[1,20]$. According to Bowlby [5], the child creates an "internal working model", i.e. a schema of the attachment object, which can be activated whenever the primary person is absent. Winnicott [31-33] considers a child's attachment to a TO to be normal, universal and even necessary for healthy development; he reports a number of clinical case histories in which subsequent psychopathology was related to the absence of TO use in childhood. There are also contrary opinions, such as that of Brody [6], who questions the function and the role of a TO and considers that its developmental and psychological meaning has been misunderstood.

TO use also seems to be influenced by social and/ or cultural factors: it is more common in western countries and urban areas, where children generally sleep alone and do not have close physical contact with the mother in the course of daily activities, than in countries where infants have close physical contact with the mother $[9,12,13]$.

The connection between breastfeeding and TO use shows similar trends to those observed for TO use and physical contact with the mother. Breastfed infants did not use TOs as often as those fed on bottled milk. The duration of breastfeeding also affected the use of a TO: children with a long-lasting breastfeeding period (over 8 months) did not use a TO as often as those with a shorter one. TOs appeared when breastfeeding ended [14, 28, 29].

The fate of the TO seems to be to lose its comforting role as the infant grows: the attachment diminishes gradually after the third birthday, or at the latest when the child begins school [31].

A study of treasured objects in school-aged children indicated that approximately half of all children between 9 and 13 years of age had formed an attachment to an object in infancy. About half of them kept it until the age of 9 years. There were no significant behavioural differences between those children who were attached to an object and those who were not [27].

Prolonged use of a TO into adolescence and adulthood may indicate psychopathology. Research with clinical populations has shown that TO use occurs mostly among individuals with borderline personality disorder $[8,19,23]$. In a study by Cardasis et al. [8], the connection between possession of a TO and a borderline personality disorder diagnosis was investigated in a psychiatric inpatient setting. Significantly more patients who reported having TOs in the hospital or at home had a diagnosis of borderline personality disorder. It is suggested that these individuals lack a sense of object constancy [8]. According to Adler [1], a major problem lies in borderline patients' inability to rely on their own internal resources to maintain and comfort themselves when faced with separation. These difficulties are related to their feelings of solitude, their problems with a vulnerable evocative memory and a tenuous capacity to maintain holding and soothing introjections of important people when experiencing the stress of separation. Bacchar et al. [4] studied childhood versus adolescence TO use and found out that the use of a TO in adolescence was significantly related to psychopathology and reduced general wellbeing. In a study of college-age students, the use of TOs and a fear of falling sleep showed a statistically significant correlation with depression [21].

\section{Purpose of the study}

In this study, we define a TO as any object which has a special value as a means of comforting and reducing anxiety - whether in childhood or in adolescence. We assume that the years of adolescence are so close to childhood that it is not unusual to be attached to an object; this is partly a normal phenomenon-the propensity to endow a certain object with the role of a TO as a comforting element. We hypothesize that particularly in those cases where the developmental 
process from childhood to adolescence involves problems, the previously experienced comforting and maintaining function of a TO may recur and the unusual relationship to the article playing the role of a TO may persist longer.

The purpose of the study was to investigate the prevalence of TO use in adolescence generally and according to gender, and the connection between depressive symptoms and TO use among adolescent boys and girls.

Permission for the study was granted by the Ethics Committee of the City of Turku and by the Turku School Board.

\section{Method}

\section{Subjects}

A total of 1,675 eighth-grade Finnish-speaking Caucasian students (794 boys and 881 girls) were recruited from normal comprehensive schools in the city of Turku, South-West Finland, with approximately 175,000 inhabitants. International schools, non-Caucasian students and schools with Swedishspeaking students were excluded. The response rate was $82.5 \%$, i.e. 1,415 forms were handed in. From these we excluded those which were left blank, gave incomplete background data (including the respondent's gender), or included non-serious answers. The total number of subjects excluded due to incomplete data was $361(25.5 \%)$. The resulting study group consisted of 1,054 adolescents: 465 boys and 589 girls. This group included 62 subjects ( 30 boys and 32 girls) who filled in the CDI questionnaire (children's depression inventory) but did not answer the question about TOs. This group did not differ from the main study group with respect to age, sex or the mean of CDI scores. The final sample of 992 subjects represents $70 \%$ of the eighth-grade students who handed in the forms and $60 \%$ of all eight-grade students in the normal Finnish-speaking comprehensive schools in the city of Turku.

The mean age of the respondents was 14.5 years (SD 0.50 ) for boys and 14.5 years (SD 0.51) for girls. The participants were more or less evenly distributed across social classes within the area of Turku. The subjects' social class was defined in terms of the guardian's occupation.

\section{Procedure and measures}

The study was carried during a normal school day. The anonymous questionnaires were distributed in the classroom in the presence of a teacher, and all the students who were in the class were invited to answer a questionnaire on background data, one on TO questions, and a separate CDI questionnaire.

Information on TOs was elicited with two questions. In the first, the student was asked to answer yes or no to the question "Do you currently have a special favourite article that you keep with you when you sleep, when you are away from home for some reason, or when you are traveling at home or abroad- for instance a soft animal, teddy-bear, doll, pillow, blanket or an other article?" If the answer was yes, in the next question the student was asked to specify what kind of thing he or she meant in the previous answer. The list of alternatives given was $\mathrm{a}=$ teddy-bear, $\mathrm{b}=$ soft animal, $\mathrm{c}=$ pillow or blanket, $\mathrm{d}=$ doll, $\mathrm{e}=$ if something else, what (with a blank space for writing in the answer). The respondents were instructed to choose only one alternative.

The children's depression inventory (CDI) was used to assess the adolescents' depressive symptoms [16]. The CDI is a 27-item self-rated symptom-oriented scale and a suitable depression measurement instrument for children and adolescents from 7 to 17 years of age. The CDI quantifies a range of depressive symptoms, including disturbed mood, hedonistic capacity, vegetative functions, self-evaluation and interpersonal behaviour. Several items concern the consequences of depression in contexts that are specifically relevant to children (e.g. school). Each CDI item consists of three choices, keyed 0,1 or 2 , with higher scores indicating an increasing tendency to depression. For each item, the meaning of each choice can be summarized by the following: $0=\mathrm{Ab}$ sence of symptom, $1=$ Mild symptom, $2=$ Definite symptom. The range of the total score is from 0 to 54 . To calculate the total CDI scores in our study we used the mean value of all questions answered for each individual (a range of $0-2$ ). In making comparisons, we used the mean value of that score for each group of adolescents. In addition to the total CDI scores, we used subscales constructed according to the factorization of the CDI scores of the Finnish school-aged population [22]: low self-confidence, anhedonia and sadness. Low self-confidence consisted of six items: hating oneself, not being loved by anyone, looking unattractive, being bad, doing everything wrong and doing very badly. Anhedonia consisted of three items: never having fun, being bothered by many things and never having fun at school. Sadness likewise consisted of three items: being sad all the time, feeling like crying and feeling lonely.

It has been shown that the CDI is a reliable and sensitive measure of depressive symptoms in children [7], but it is not recommended for use as a sole instrument in screening psychiatric disturbances [17]. The CDI is a measure of non-specific psychopathol- 
ogy rather than of pure depression [2]. The validity of the CDI in screening depressive symptoms among children and adolescents has also been demonstrated in Finnish studies [18].

\section{Data analyses}

The data were analysed using the Statistical Package of Social Sciences 13.0 and 16 (SPSS 13.0 and 16).

First, the whole study group was divided into those who did not possess a transitional object (non-TO-users) and those who did (TO-users). Girls and boys were then separately divided into TO-users and non-TO-users. Further analyses compared non-TO-users to TO-users in the group as a whole and for each gender separately. The categorical variables were analysed with cross-tabulations and Pearson's chi-square test. The differences between the mean values of the CDI total scores and its subscales by TO use and gender were analysed with an independent sample $t$ test and controlled with a nonparametric test (Mann-Whitney $U$ test).

\section{Results}

\section{Prevalence of TO use}

Out of the whole study group, $28.7 \%(n=285)$ had some kind of TO at bedtime or when away from home or traveling. The figure for girls was $37 \%(n=208)$ compared to only $18 \%(n=77)$ for boys (Table 1$)$. The gender difference was significant $(P<0.001)$.

Of all those having a TO, $62 \%(n=176)$ listed a teddy-bear or other soft animal as their TO. A total of $12 \%(n=36)$ of all the students who had any TO named a pillow or blanket and only $0.7 \%(n=2)$ a doll. A group of $22 \%(n=62)$ answered that their TOs were some other item than those named in the questionnaire (for instance a book or a pen). A total of $72 \%$ of girls with a TO had a teddy-bear or other soft animal as a TO, while $49 \%$ of boys with a TO used other things, such as books, pens or toys. The gender differences were statistically significant. More details are shown in Table 2.

\section{Depressive symptoms and T0 use}

There was no gender difference in the CDI total scores; boys and girls did not differ in the stage of symptomatology in depression (mean 0.34 , SD 0.22 and mean 0.33 , SD 0.28 , respectively).

In the subscales boys showed more significant anhedonia than girls $(P=0.000)$, while girls had significantly lower self-confidence than boys $(P=0.004)$. With regard to sadness there was no difference between boys and girls.

In the group of TO-users the mean of the total CDI scores was 0.36 (SD 0.27), while in the group of non users it was 0.33 (SD 0.24). There was a non-significant trend $(P=0.053)$ in CDI total scores between TO-users and non-users.

Table 1 The prevalence of TO use in adolescents by gender $(N=992)$

\begin{tabular}{|c|c|c|c|c|c|c|}
\hline \multirow[t]{2}{*}{ T0 use } & \multicolumn{2}{|c|}{ Boys $(n=433)$} & \multicolumn{2}{|c|}{ Girls $(n=559)$} & \multicolumn{2}{|c|}{ Total $(N=992)$} \\
\hline & $\%$ & $n$ & $\%$ & $n$ & $\%$ & $n$ \\
\hline Uses a TO & 17.8 & 77 & 37.2 & $208^{* * *}$ & 28.7 & 285 \\
\hline Does not use a T0 & 82.2 & 356 & 62.8 & 351 & 71.3 & 707 \\
\hline
\end{tabular}

The differences between boys and girls in T0-using was investigated by Pearson's chi-square test

${ }^{*} P \leq 0.05,{ }^{* *} 0.001<P \leq 0.01$, ${ }^{* *} P \leq 0.001$

Table 2 Articles named as having role of T0 by adolescents using one $(N=285)$

\begin{tabular}{|c|c|c|c|c|c|c|}
\hline \multirow[t]{2}{*}{ T0 named } & \multicolumn{2}{|c|}{ Boys $(N=77)$} & \multicolumn{2}{|c|}{ Girls $(N=208)$} & \multicolumn{2}{|c|}{ Total $(N=285)$} \\
\hline & $\%$ & $n$ & $\%$ & $n$ & $\%$ & $n$ \\
\hline Teddy-bear or other soft animal & 35.1 & 27 & 71.7 & $149^{* * *}$ & 61.8 & 176 \\
\hline Blanket or pillow & 13.0 & 10 & 12.5 & 26 & 12.6 & 6 \\
\hline Doll & 0 & 0 & 1.0 & 2 & 0.7 & 2 \\
\hline Other (book, pen, toy etc.) & 49.4 & 38 & 11.5 & $24^{* * *}$ & 21.8 & 62 \\
\hline Not specified & 2.6 & 2 & 3.4 & 7 & 3.2 & 9 \\
\hline
\end{tabular}

Significance of differences between genders in naming T0 tested by Pearson's chi-square test

${ }^{*} P \leq 0.05,{ }^{* *} 0.001<P \leq 0.01,{ }^{* * *} P \leq 0.001$ 
Table 3 Mean (M) values and standard (SD) deviations for total CDI scores (range $0-2$ ) and CDI subscales by gender in whole study group, non-T0 using groups and T0-using groups

\begin{tabular}{|c|c|c|c|c|}
\hline Study group & $\begin{array}{l}\text { Total CDI } \\
\text { M (SD) }\end{array}$ & $\begin{array}{l}\text { Low self confidence } \\
\text { M (SD) }\end{array}$ & $\begin{array}{l}\text { Anhedony } \\
\text { M (SD) }\end{array}$ & $\begin{array}{l}\text { Sadness } \\
\text { M (SD) }\end{array}$ \\
\hline The whole study group $N=992$ & $0.34(0.25)$ & $0.32(0.32)$ & $0.45(0.37)$ & $0.14(0.28)$ \\
\hline Boys $n=433(43.6 \%)$ & $0.34(0.28)$ & $0.29(0.33)$ & $0.51(0.39)$ & $0.13(0.27)$ \\
\hline Girls $n=559(56.4 \%)$ & $\begin{array}{l}0.33(0.22) \\
P=0.67\end{array}$ & $\begin{array}{l}0.35(0.30) \\
\boldsymbol{P}=\mathbf{0 . 0 0 4}^{* *}\end{array}$ & $\begin{array}{l}0.41(0.36) \\
\boldsymbol{P}=\mathbf{0 . 0 0 0}^{* * *}\end{array}$ & $\begin{array}{l}0.16(0.29) \\
P=0.062\end{array}$ \\
\hline Non-TO-users $n=707$ (71.3\%) & $0.33(0.24)$ & $0.31(0.30)$ & $0.46(0.41)$ & $0.12(0.26)$ \\
\hline T0-users $n=285(28.7 \%)$ & $\begin{array}{l}0.36(0.27) \\
P=0.053\end{array}$ & $\begin{array}{l}0.34(0.33 \\
P=0.25\end{array}$ & $\begin{array}{l}0.45(0.36) \\
P=0.90\end{array}$ & $\begin{array}{l}0.20(0.32) \\
P=0.001^{* * *}\end{array}$ \\
\hline Non-T0-using boys $n=356$ (82.2\%) & $0.33(0.27)$ & $0.29(0.32)$ & $0.50(0.48)$ & $0.12(0.26)$ \\
\hline T0-using boys $n=77(17.8 \%)$ & $\begin{array}{l}0.38(0.34) \\
P=0.19\end{array}$ & $\begin{array}{l}0.29(0.38) \\
P=0.90\end{array}$ & $\begin{array}{l}0.58(0.37) \\
P=0.16\end{array}$ & $\begin{array}{l}0.18(0.35) \\
P=0.14\end{array}$ \\
\hline Non-T0-using girls $n=351$ (62.8\%) & $0.32(0.21)$ & $0.34(0.30)$ & $0.41(0.37)$ & $0.13(0.26)$ \\
\hline T0-using girls $n=208$ (37.2\%) & $\begin{array}{l}0.36(0.23) \\
P=0.8\end{array}$ & $\begin{array}{l}0.36(0.29) \\
P=0.40\end{array}$ & $\begin{array}{l}0.41(0.35) \\
P=0.91\end{array}$ & $0.21(0.32)$ \\
\hline
\end{tabular}

$\mathrm{CDI}$, the children depression inventory; low self confidence, subscale of CDI; anhedony, subscale of CDI; sadness, subscale of CDI

Significance of differences in means between groups tested by $T$ test and controlled by non-parametric Mann-Whitney $U$ test

${ }^{*} P \leq 0.05,{ }^{* *} 0.001<P \leq 0.01,{ }^{* * *} P \leq 0.001$

With regard to the CDI subscales, TO-users showed markedly more sadness than the non-users $(P=0.001)$ (TO-users mean 0.20, SD 0.32; non-users 0.12 , SD 0.26). Anhedonia and low self-confidence were not related to TO use.

TO-using girls had a higher CDI total score than non-TO-using ones. There was a non-significant trend $(P=0.08)$.

In the group of TO-using girls, sadness was markedly common compared to non-TO-using girls $(P=0.002)$. Low self-confidence and anhedonia were not connected to TO use in girls. TO-using boys had higher means in the total CDI score, in anhedonia and in sadness than non-TO-using boys, but the differences were not statistically significant. The results are presented in Table 3.

\section{Discussion}

It has been suggested that more research is needed concerning the use of TO after childhood, because of its possible role as a visible representation and marker of mental distress $[3,4]$. There have been only few studies exploring the use of TOs in stressful situations in adolescence, or the general occurrence of TOs at that age. In our study the use of a TO in adolescence was common, especially among girls. The prevalence of TO use in the normal adolescent population was higher than that found by Bacchar et al. [4]: $27 \%$ compared to their $22 \%$. This may be due to the younger age of our group, 14.5 versus 16.7. The higher TO use among girls than among boys, and the use of soft toys in particular, may reflect the emotional life of girls at the age of 14 .
Our study does not totally confirm the results of the study by Markt and Johnson [21], who found a strong connection between TO use and depression in college-age students: the indications we found were similar but weaker. We did find some connections between depressive symptoms and TO use: sadness, among girls in particular, showed a clear connection. Developmental regression in youth is a common phenomenon and a transitional period before autonomy. Adolescents who are in developmental regression and feel sad may practice a similar TO use as in childhood. The use of a TO may work in the same way as in childhood, as a defence against anxiety, especially of separation and depressive types.

The mean scores of depressive symptoms in our study did not differ by gender. This is similar to previous studies $[18,22,25]$. In general, the boys in our study reported more symptoms of anhedonia and girls of low self-confidence. With regard to boys' anhedonia this result is consistent with the results of an earlier Finnish study [22]. In our study girls had lower self-confidence than boys. The psychiatric symptomatology of boys is mostly extroverted, while among girls it is of a more introverted and emotional type. The inability to gain pleasure from enjoyable experiences may make the boys behave idly and react extrovertedly to obtain some response. Previous studies of self-image in girls have also shown a higher correlation with depressive symptoms than in boys [11].

\section{Limitations}

One of the limitations of our study was the rather large number of students absent from school on the 
day of the study. Because of the rule of anonymity it was not possible to re-test those who had been absent. The number of excluded students was also rather large; these groups may have included students with more problems than those included. Another limitation which may weaken our study is the larger number of girls participating. Our final sample was nevertheless large in both genders and represented the whole city, with children from all social classes.

\section{Practical meaning of the study of TO use in adolescence}

Although prolonged attachment to a TO is not as such an indication of psychopathology, it may denote a vulnerability to adolescent perturbation and difficulty in coping with the emotionally laden developmental process of the transition from childhood to adolescence and adulthood. The presence of a TO in fact offers new possibilities for therapeutic applications in confronting adolescents with mild or moderate developmental and psychological problems. Winnicott [31-33] and Roland [24] suggest that the psychological meanings of TO use in childhood are closely allied with imagination, playfulness, creativity, art and religion in later years and over the whole lifetime. Child therapy has a long tradition of using play, imagination and creativity in working with children [15]. Dockar-Drysdale [10] describes work in a therapeutic unit for severely emotional disturbed teenage boys, where the therapists and other staff members use TOs as part of caring. "Teddy-bear groups" were started for boys who were too avoidant to speak or communicate with the therapist, other staff members or the other boys. Communicating first through teddy-bears helped these avoidant boys to join the group and to gradually start to speak as themselves and about themselves. The therapists also use TOs as part of the therapy process in the boys' individual therapy. Taking care of one's TO together with the therapists, the boy is able to experience true comfort, caring and maintaining [10]. It is important to explore the use of TOs as an element in adolescent therapy. Perhaps a TO could be a supporting element not only in adolescent therapy but also in daily life; no longer as merely a plaything, but as an object offering a possibility of symbolic function which has not yet been developed.

The connection found in our study between girls' sadness and TO use was very clear. Because of the sparse literature on this subject and the pioneering nature of this work, further comparisons to earlier studies cannot be drawn. Further work is needed for a clear understanding of the role of TOs in the world of adolescents.

\section{References}

1. Adler G (1993) The psychotherapy of core borderline psychopathology. Am J Psychother 47:194-205

2. Aronen ET, Soininen M (2000) Childhood depressive symptoms predict psychiatric problems in young adults. Can J Psychiatry 45:465-470

3. Arthern J, Madill A (2002) How do transitional objects work? The client's view. Psychother Res 12:369-388

4. Bacchar E, Canetti L, Galilee-Weisstub E, Kaplan-DeNour A, Shalev A (1998) Childhood vs. adolescence transitional object attachment, and its relation to mental health and parental bonding. Child Psychiatry Hum Dev 28:149-167

5. Bowlby J (1969) Attachment and loss, vol 1. Basic Books, New York

6. Brody S (1980) Idealization of a phenomenon. Psychoanal Q 49:561-605

7. Brooks SJ, Kutcher S (2001) Diagnosis and measurement of adolescent depression: a review of commonly utilized instruments. J Child Adolesc Psychopharmacol 11:341-376

8. Cardasis W, Hochman JA, Silk R (1997) Transitional objects and borderline disorder. Am J Psychiatry 154:250-255
9. Daws D (1993) Feeding problems and relationship difficulties: therapeutic work with parents and infants. J Child Psychother 19:69-83

10. Dockar-Drysdale B (1990) The provision of primary experience: Winnicottian work with children and adolescents. Free Associations Books, London

11. Erkolahti R, Ilonen T, Saarijärvi S, Terho P (2003) Self-image and depressive symptoms among adolescents in a nonclinical sample. Nord J Psychiatry 57:309-312

12. Gaddini R, Gaddini E (1970) Transitional objects and the process of individuation: a study in three different social groups. J Am Acad Child Psychiatry 9:347-365

13. Hong M, Townes BD (1976) Infants' attachments to inanimate objects. A cross cultural study. J Am Acad Child Psychiatry 15:49-61

14. Ikeuchi H, Fujihara T (2004) Social psychological determinants of appearance of transitional objects: focusing of nursing environment. Jpn J Soc Psychol 19:184-194
15. Jernberg, Ann M (1979) Theraplay. Jossey-Bass, San Francisco

16. Kovacs M (1992) Children's depression inventory manual. Multi-Health Systems, North Tonawanda

17. Kresanov K, Tuominen J, Piha J, Almqvist F (1998) Validity of child psychiatric screening methods. Eur Child Adolesc Psychiatry 7:85-95

18. Kumpulainen K, Räsänen E, Henttonen I, Hämäläinen M, Roine S (2000) The persistence of psychiatric deviance from the age of 8 to the age of 15 years. Soc Psychiatry Psychiatr Epidemiol 35:5-11

19. Laporta LD (1997) Borderline personality disorder and transitional objects. Am J Psychiatry 154:1484-1485

20. Mahler MS, Pine F, Bergman A (1975) The psychological birth of the human infant: symbiosis and individuation. Basic Books, New York

21. Markt C, Johnson M (1993) Transitional objects, pre-sleep rituals, and psychopathology. Child Psychiatry Hum Dev 23:161-173

22. Moilanen I (1991) Components of childhood depression. Rep Psychiatr Fenn 91:85-91 
23. Morris H, Gunderson JG, Zanarini MC (1986) Transitional object use and borderline psychopathology. Am J Psychiatry 143:1534-1538

24. Roland A (1971) Imagery and symbolic expression in dreams and art. Int J Psychoanal 53:531-539

25. Samm A, Värnik A, Tooding LM, Sisask M, Kölves $\mathrm{K}$, von Knorring AL (2007) Children's depression inventory in Estonia: single items and factor structure by age and gender. Eur Child Adolesc Psychiatry 14 Sep [Epub ahead of print]

26. Shafii T (1986) The prevalence and use of transitional objects: a study of 230 adolescents. J Am Acad Child Psychiatry 25:805-808
27. Sherman M, Hertzig M, Austrian R, Shapiro T (1981) Treasured objects in school-aged children. Pediatrics 68:379-386

28. Tabin JK (1992) Transitional objects as objectifiers of the self in toddlers and adolescents. Bull Menninger Clin 56:209-220

29. Viberg L,Viberg M (2003) Nallen I psykologi. En prospektiv studie med focus på barns använding av övergångsobjekt. Akademisk avhandling. Lunds Universitet. Samhällsvetenskapliga fakulteten

30. Winnicott DW (1953) Transitional objects and transitional phenomena. Int J Psychoanal 34:89-96
31. Winnicott DW (1971) Playing and reality. Basic Books, New York

32. Winnicott DW (1965) The maturational processes and the facilitating environment. International Universities Press, New York

33. Winnicott DW (1966) The location of cultural experiences. Int J Psychoanal 48:368-372 